\title{
THERMAL MODE OF SAPPHIRE SHELLS AND DEPTH OF MODULATION OF RADIATION OF PULSED-PERIODIC SOURCES OF INFRARED RADIATION
}

\author{
V.M. Gradov ${ }^{1}$ \\ S.V. Gavrish ${ }^{2}$ \\ gradov@bmstu.ru \\ svgavr@list.ru \\ I.V. Rudakov ${ }^{1}$ \\ irudakov@yandex.ru \\ ${ }^{1}$ Bauman Moscow State Technical University, Moscow, Russian Federation \\ ${ }^{2}$ JSC Special Design Bureau ZENIT, Moscow, Zelenograd, Russian Federation
}

\begin{abstract}
The factors that determine the two most important characteristics of powerful infrared radiation sources, peak power and the depth of the radiation modulation in the spectral regions $1.8-4.2 \mu \mathrm{m}$ and $3.0-5.0 \mu \mathrm{m}$, are investigated. The distributions of temperature fields in the discharge channel and in the system of two sapphire shells separated by a gap with the gas are given. It is shown that in the pulsed-periodic mode of operation with a pulse repetition rate of $450 \mathrm{~Hz}$, the temperature field in the heated shells is practically stationary and causes, at high electric powers, the appearance of a constant radiation of the material of shells. As a result, the fraction of the discharge radiation in the total radiation of the source decreases, which negatively affects the depth of modulation. The temperature drop over the wall thickness is much smaller than the temperature difference in the gas gap. Data on the time dependence and the structure of heat losses on the inner shell are given. The spectral dependence of the depth of modulation is obtained under conditions of different cooling intensities, it is established that starting from about 4.9-5.2 $\mu \mathrm{m}$, the lamp practically loses modulation properties in the infrared region. In this case, a sharp decrease in the depth of modulation begins from wavelengths of about $3.5 \mu \mathrm{m}$. The methods and design solutions that contribute to the increase of the modulation depth due to the reduction of the constant component of the radiation and the increase in the peak power of the radiation are considered in detail. The results obtained make it possible to reduce the laboriousness of experimental work in designing devices of this type
\end{abstract}

\section{Keywords}

Radiation source shell, temperature field, modulation depth, peak radiation power, discharge, infrared, simulation, spectra

Received 25.01.2018

(C) Author(s), 2019 
Introduction. Pulsed-periodic sources of infrared radiation with wavelengthsin the range of $1.8-4.2 \mu \mathrm{m}$ and $3-5 \mu \mathrm{m}$ are radiation generators in the composition of optical-electronic systems of aircraft active protection from homing weapons that react to the thermal radiation of the protected object engine [1-5]. These sources are a special type of discharge tube lamps in which the discharge in a mixture of cesium and mercury vapors with xenon is stabilized by coaxially placed sapphire shells, and the gap between the shells is filled with a mixture of inert gases that provide the necessary heat from the inner tube [6]. The lamp is cooled by airflow. The radiation source is included in the external LCR circuit, with the help of which voltage pulses with a fixed duration and frequency are periodically initiated. Due to this, radiation modulation occurs with given operational parameters for the pulse duration, frequency, peak radiation power and radiation modulation depth in the working spectral ranges, which ensures the specified level of object protection $[4,5]$. The peak power and modulation depth of the radiation are the key characteristics of the radiation sources under consideration, which determine their suitability for use in stations of optical-electronic countermeasures.

The peak radiation power is the maximum pulse power of the source, measured in watts per steradian. Peak power is always reached at the end of the voltage pulse at the maximum of the sawtooth current. The total radiation power of the lamp consists of a variable in the pulse of the discharge power and the constant component of the radiation produced by the inertia thermally heated semitransparent shells and depends on their temperature state. The latter is determined by the balance between radiant and conductive energy fluxes from the discharge, heat release due to the sapphire's own radiation at high temperatures and heat transfer from the outer surface. In principle, with strong heating, the radiation of the shells can affect the discharge, heating the plasma and changing its characteristics (for example, ohmic resistance). The modulation depth is the ratio of the difference between the peak radiation power and the constant radiation component to the peak radiation power in a given spectral range. Both characteristics are related to each other and depend on a large number of parameters: plasma pressure, composition of components, parameters of the discharge circuit, electric voltage across the capacitor, arc duty current, dimensions of the discharge tube, thickness of the shells, flow rate of the cooler, its direction of supply to the lamp and etc. Optimization of characteristics is greatly simplified due to the joint conducting of full-scale and numerical experiments.

Formulation of the problem. A mathematical model of the source describes [7] processes in a discharge multicomponent non-stationary weakly 
nonideal plasma of a mixture of cesium, mercury and xenon vapor, a system of two cylindrical translucent shells separated by a gas gap in an external electric discharge LCR circuit with a high-current transistor switch taking into account radiation transfer in the discharge and shells.

The model consists of a database of material plasma functions, precisely tied to temperature, pressure and component ratios, and structural elements. In most cases, the thermodynamic, transport and optical characteristics of the plasma are obtained by calculation. The coefficients of electrical conductivity, electronic thermal conductivity, heavy particles thermal conductivity, enthalpy, and optical absorption coefficient were calculated according to [8-11].

The main radiation processes that determine the absorption coefficient of a multicomponent atomic plasma are photoionization of atoms and ions, reverse inhibition of electrons in the fields of neutral particles and ions, discrete transitions of bound electrons. The discrete spectrum is formed as a result of line overlap. These lines are broadened by various mechanisms (Stark, resonant, Doppler, Van der Waals mechanisms [7]). The Voigt line profile is considered. All information on the quantum characteristics of the energy levels of cesium, mercury and xenon, necessary for calculating the statistical sums, the probabilities of spontaneous radiative transitions, photoionization cross sections, and other calculations was borrowed from [12-15].

The complex mathematical model of the device is implemented by numerical methods $[7,16,17]$.

Results of simulation and experiment. The following are the results of temperature regimes calculations and radiation modulation depth of the optimized lamp with a discharge gap size of $0.55 \times 3.5 \mathrm{~cm}$ with a technological pulse repetition rate of $450 \mathrm{~Hz}$. The parameters of the electric circuit are as follows: inductance $8 \mu \mathrm{H}$, active resistance of the circuit is $0.026 \mathrm{Ohm}$, current of the pilot arc $2 \mathrm{~A}$, duration of the voltage pulse on the lamp $\sim 270 \mu$ s; the content of cesium and mercury in the discharge is 1.32 and $2 \mathrm{mg}$; wall thickness and clearance of 0.2 and $0.15 \mathrm{~cm}$. Consider the steady state operation, which is achieved during the passage of about ten pulse packets to form a regular thermal regime in the discharge and more than 32000 packets in the wall. This significantly increases the complexity of the computational experiment.

Note that the calculations of the temperature field in the sapphire wall were carried out [18] during the analysis of the heat resistance of the shell of a xenon water-cooled lamp in the transition mode at the stage of switching on the lamp.

Figure 1 shows the temperature distributions in the discharge and the system of lamp shells during a pulse. 


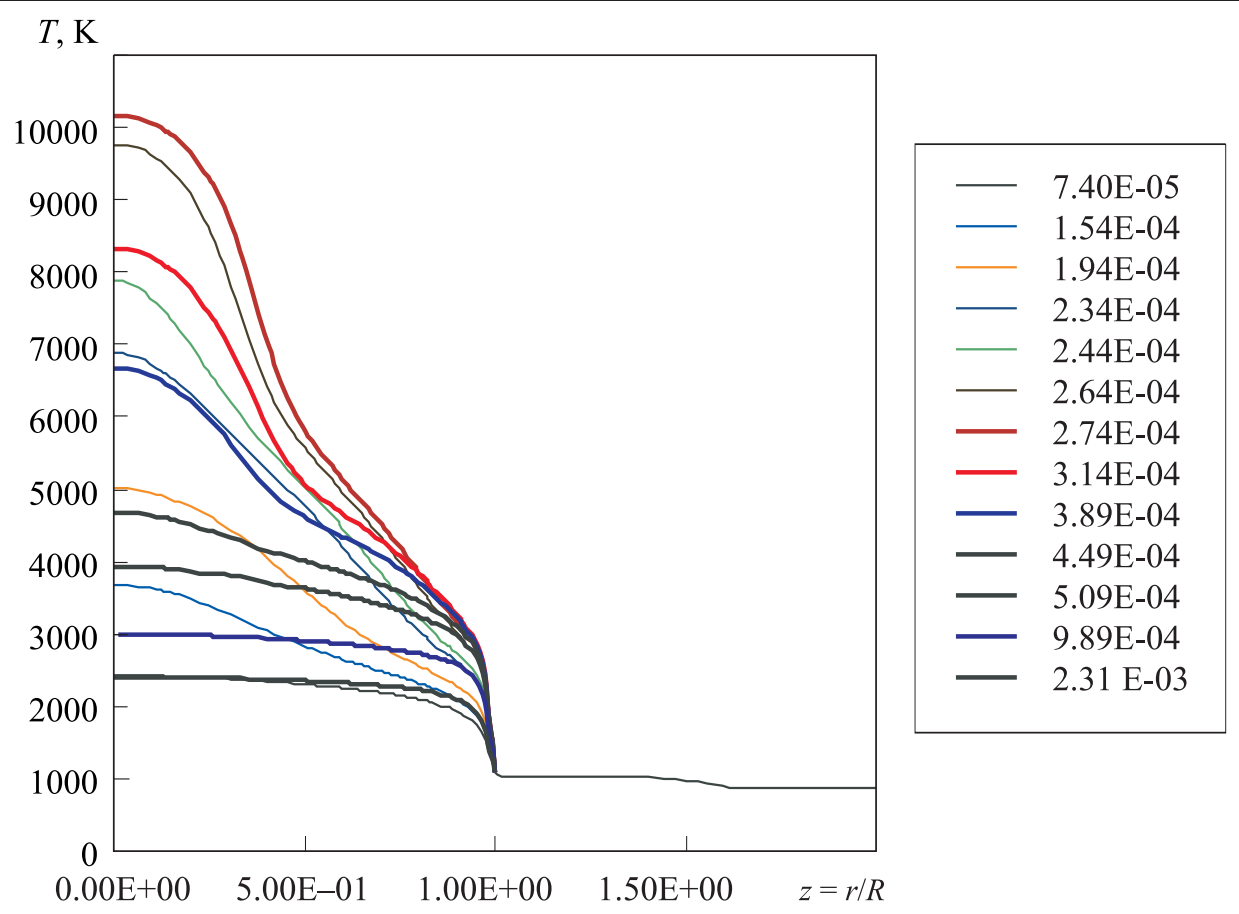

Fig. 1. Temperature profiles in the discharge and the system of shells at a voltage of $140 \mathrm{~V}$ on the capacitor and heat transfer coefficient $\alpha=0.001 \mathrm{~W} /\left(\mathrm{cm}^{2} \cdot \mathrm{K}\right)$; numbers denoting curves are current time; bold lines are time points after the lamp voltage is turned off (the plasma cools down)

The temperature field in the discharge (axial temperature and profile shape) changes significantly during the pulse. At the same time, the temperature field in the shells is completely stabilized and in this mode it practically does not change from pulse to pulse, nor during the period of the pulse passage. At a frequency of $450 \mathrm{~Hz}$, due to the high thermal inertia of the material, the wall temperature responds poorly to an abrupt change in the heat flux from the discharge (Fig. 2), which loads the inner shell, as well as to nonstationary volumetric heat release due to the absorption of discharge radiation in the translucency region.

The heat flux (Fig. 2) is formed by the components due to plasma thermal conductivity and radiation output beyond the long and short wave-length transmission limits of leucosapphire, which are $5.5 \mathrm{~nm}$ and $0.18 \mu \mathrm{m}$, corresponding to the technologically real properties of this material. The shortwave component of heat fluxes was taken into account, since near the maximum current in the central region of the discharge the temperature exceeds $(8-9) \cdot 10^{3}$ K. From Fig. 2 it follows that the heat flux from the discharge changes significantly with increasing electrical power. Thus, a change in power from 


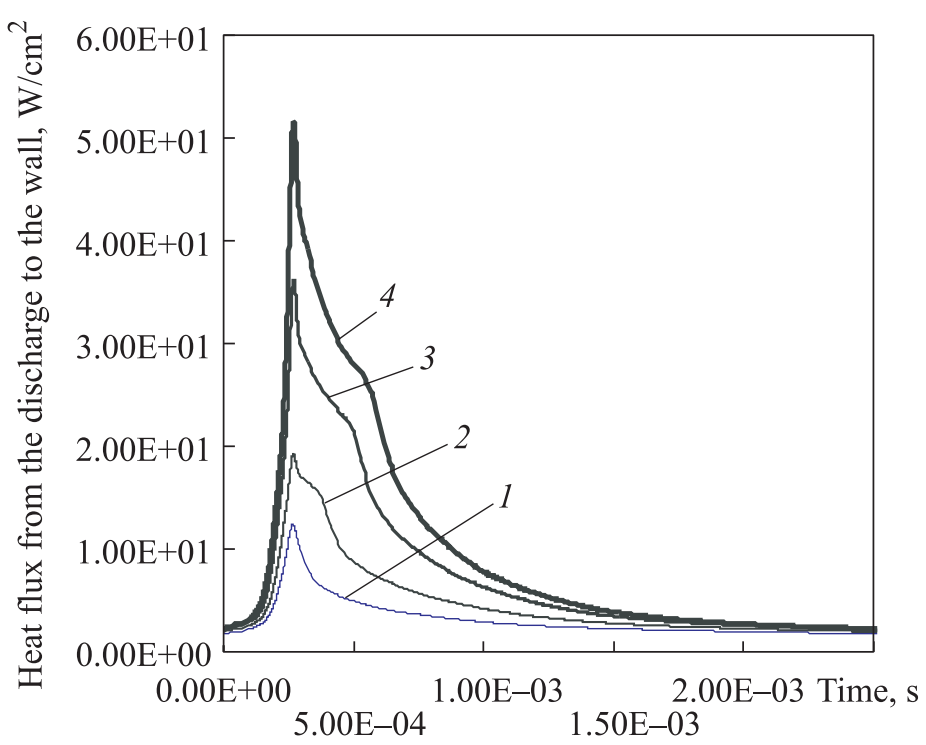

Fig. 2. The total heat flux from the discharge to the wall depending on time; average electrical power is 160 (curve 1); 235 (2); 365 (3); $460 \mathrm{~W} / \mathrm{cm}(4)$

235 to $460 \mathrm{~W} / \mathrm{cm}$ changes the flow at the maximum by almost 2.5 times. It can be seen that the flow in time has a steep leading edge, at which its fast (70-90 $\mu \mathrm{s})$ rises to a maximum, then after zeroing the voltage, there occurs at first a fairly rapid decrease in the flow and then a slow decrease as the temperature field transforms and the arc reaches a standby mode.

The temperature difference on the inner surface of the discharge tube and the outer surface of the outer shell with increasing average electrical power varies between $110-190 \mathrm{~K}$ with a heat transfer coefficient $\alpha=0.001 \mathrm{~W} /\left(\mathrm{cm}^{2} \cdot \mathrm{K}\right)$ and $170-280 \mathrm{~K}$ with $\alpha=0.01 \mathrm{~W} /\left(\mathrm{cm}^{2} \cdot \mathrm{K}\right)$ (Fig. 3). The main temperature gradient falls on the gap (Fig. 4), while if the temperature gradient in the wall at $\alpha=0.001 \mathrm{~W} /\left(\mathrm{cm}^{2} \cdot \mathrm{K}\right)$ falls in the range of $5-10 \mathrm{~K}$, then in the gap it is $125-170 \mathrm{~K}$. At increasing $\alpha$ to $0.01 \mathrm{~W} /\left(\mathrm{cm}^{2} \cdot \mathrm{K}\right)$, the temperature gradient due to the nonlinearity of the thermal conductivity of the mixture in the gap and sapphire increases to $240 \mathrm{~K}$. The temperature gradient at the boundaries of the gap changes as the ratio of neon and helium changes between the shells. The use of a cleaner shell material, in which the long-wavelength transmission limit is shifted to 6-6.5 $\mu \mathrm{m}$, reduces the heat flux, which loads the shell, and facilitates their thermal regime.

The spectral composition of the radiation absorbed and emitted by the shells is determined by the spectral distributions of the discharge radiation, the absorption coefficient of the wall material and the distribution function of 
Fig. 3. Temperatures on the inner surface of the inner shell (curves 1 and 2) and on the outer surface of the outer shell $(3,4)$ depending on the average electrical power; curves 1,3 are $\alpha=0.001 \mathrm{~W} /\left(\mathrm{cm}^{2} \cdot \mathrm{K}\right)$; curves 2,4 are $\alpha=0.01 \mathrm{~W} /\left(\mathrm{cm}^{2} \cdot \mathrm{K}\right)$
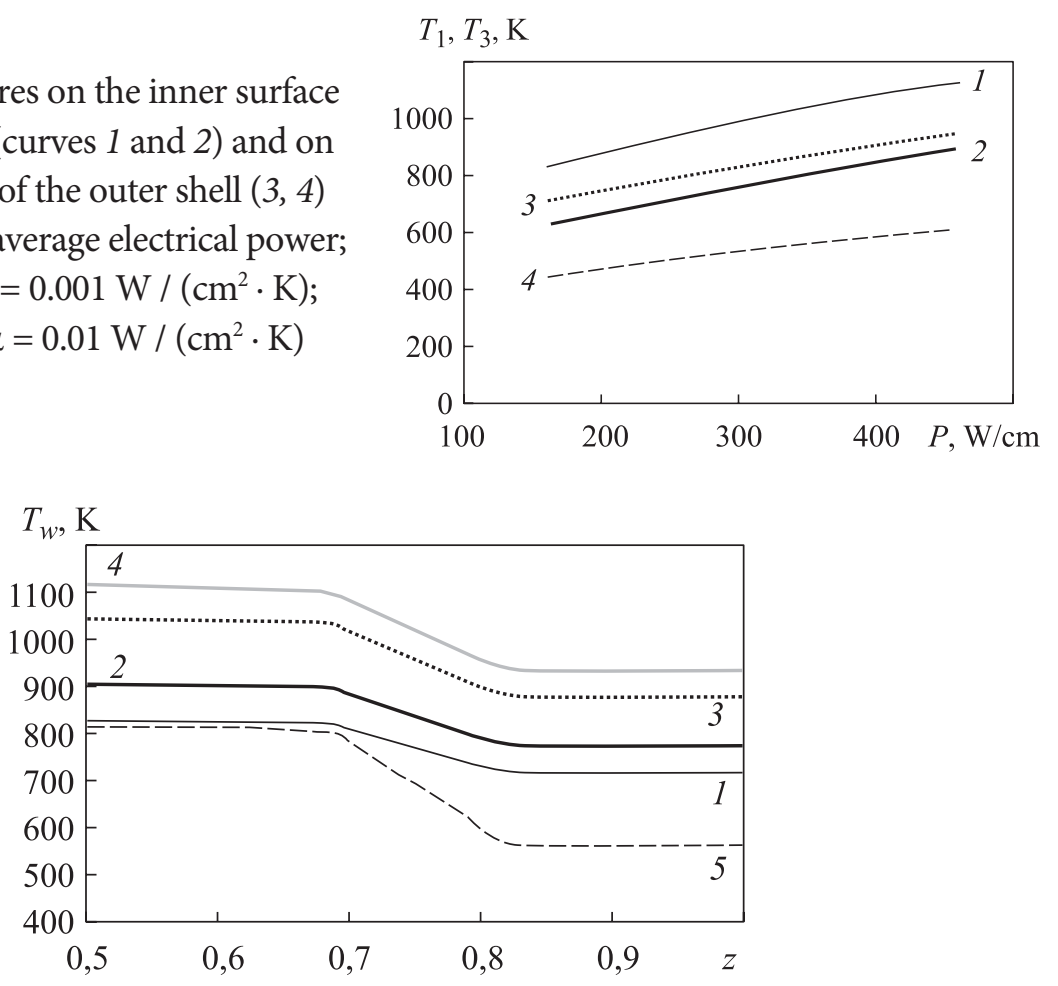

Fig. 4. Temperature field in the shell system: curves $1-4$ are $\alpha=0.001 \mathrm{~W} /\left(\mathrm{cm}^{2} \cdot \mathrm{K}\right)$; curve 5 is $\alpha=0.01 \mathrm{~W} /\left(\mathrm{cm}^{2} \cdot \mathrm{K}\right)$; $P=160$ (curve 1), 235 (2), 365 (3, 5), $460 \mathrm{~W} / \mathrm{cm}(4)$

Planck's equilibrium radiation, which is the product of the absorption coefficient, according to Kirchhoff's law, determines the emissivity of the material. The peak and pulse-average spectral distributions of discharge radiation are shown in Fig. 5. The average value of the radiation flux was determined as the product of the radiation energy per pulse and the pulse repetition rate. Shown in Fig. 5 average and peak values differ by more than an order of magnitude. The main fraction of the discharge radiation is concentrated in the region of wavelengths less than 2 microns. This region makes the main contribution to the bulk absorption in the walls. Note that the curve of the peak radiation power clearly shows quite powerful ultraviolet spectral components that are not in the spectrum of the average radiation. This indicates that the contribution of radiation from the UV region in the region of the maximum current to the total radiation energy per pulse in the same region is sufficiently small.

Shells are heated to temperatures at which they themselves begin to radiate noticeably. At the same time, in the long-wavelength region, where the absorption coefficient of leucosapphire is sufficiently large, the radiation of the 


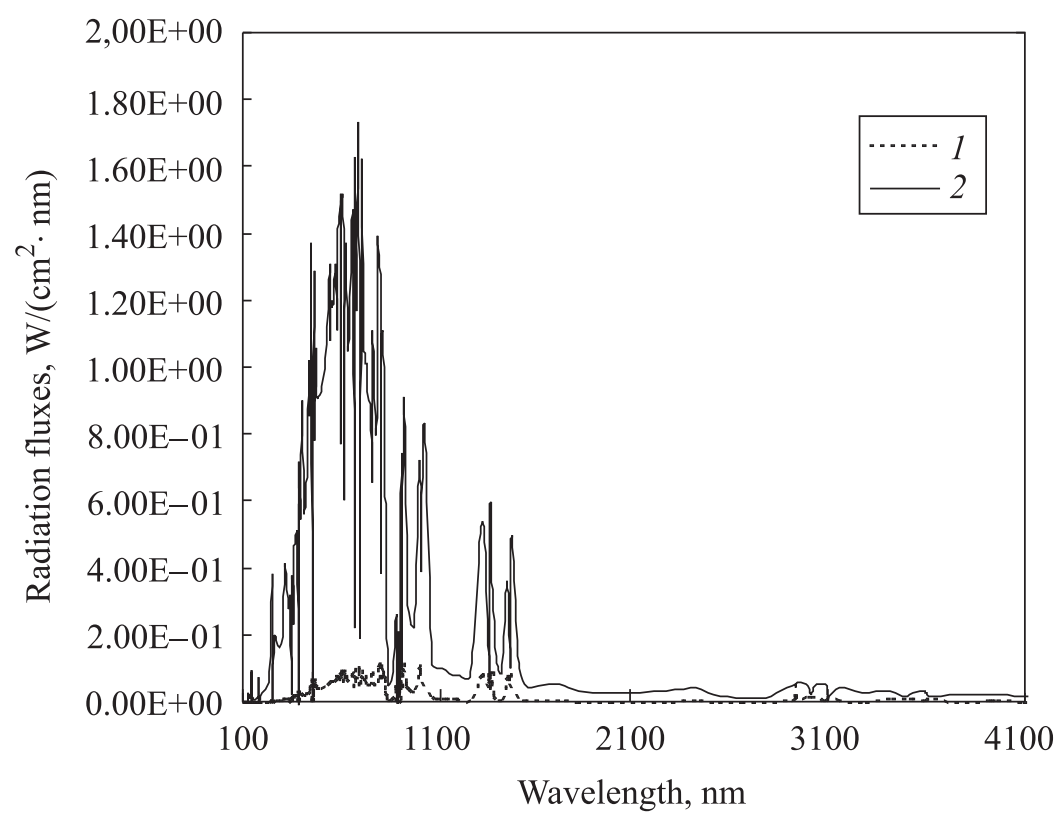

Fig. 5. The average (1) and peak (2) spectral radiation fluxes of the discharge; average electric power $P=235 \mathrm{~W} / \mathrm{cm}$

shells may exceed the discharge radiation, while in the short-wavelength region of the spectrum, the walls act as a plasma radiation absorber (the absorption coefficient of sapphire has a minimum value at wavelengths of about 2 microns and increases towards the UV area). As the electric power grows, the radiation of the shells becomes noticeably stronger (Fig. 6), approximately in this ratio - an increase in power of 2 times leads to an increase in the emission of the walls at the spectrum maximum by 2.5 times with a shift of this maximum to the shortwave region. At high temperatures $(\sim 1800 \mathrm{~K})$, due to a sharp increase in the absorption coefficient of the wall material, two maxima appear in the emission spectrum of the shells.

For providing the necessary depth of radiation modulation in the IR region, it turns out that the desire to increase the peak radiation power by increasing the electrical load on the source is accompanied by a very rapid growth of the constant radiation component of the shells, and in an everexpanding spectrum range. As a result, with an increase in electrical power, the depth of modulation of radiation may even decrease.

As for the structure of the balance of power discharged by the shells, it was found that with increasing electric power, the contribution to the total emission of the radiant component increases, and the role of this mechanism is more significant with smaller heat transfer coefficients. With the increase in the latter, the intensity of convective heat removal significantly increases and

10 ISSN 0236-3941. Вестник МГТУ им. Н.Э. Баумана. Сер. Машиностроение. 2019. № 1 
Thermal Mode of Sapphire Shells and Depth of Modulation of Radiation...

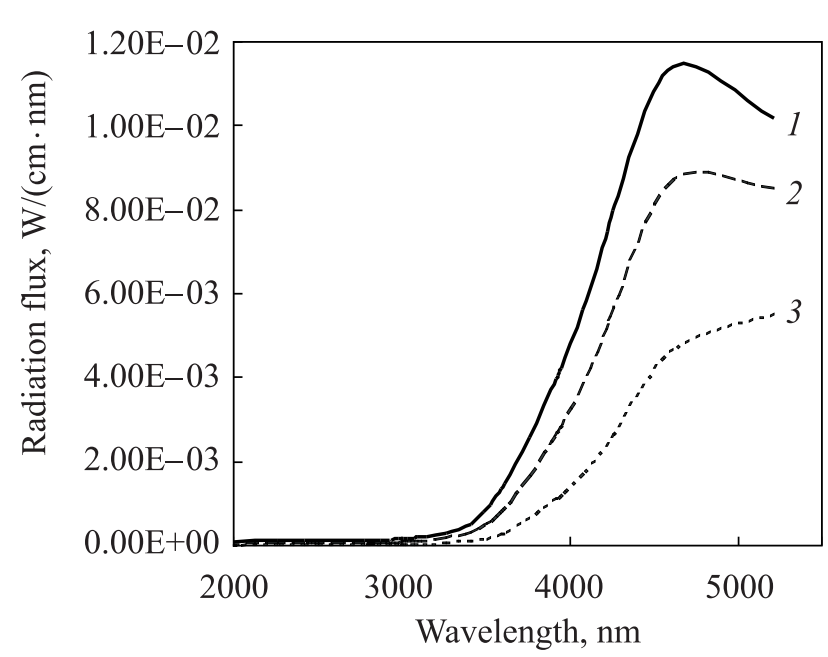

Fig. 6. Spectral distribution of lamp shells radiation; $\alpha=0.001 \mathrm{~W} /\left(\mathrm{cm}^{2} \cdot \mathrm{K}\right)$; average electric power $P_{s}=460$ (curve 1); 360 (2); $235 \mathrm{~W} / \mathrm{cm}$ (3)

the contribution of radiation power release decreases. This circumstance provides the key to considering methods and techniques for increasing the modulation depth of radiation in given regions of the spectrum.

The dependence of the radiation modulation depth on the wavelength, electrical power and cooling conditions is shown in Fig. 7. It can be seen that, starting from about 4.9-5.2 $\mu \mathrm{m}$, the lamp practically loses its modulation properties. At the same time, the modulation depth of the radiation decreases sharply as it moves to the IR region from wavelengths of $\sim 3.5 \mu \mathrm{m}$. At shorter wavelengths, the dependence of the modulation depth on the wavelength is weak, with the exception of narrow sections near reabsorbed resonance lines. An increase in the heat transfer coefficient leads to a decrease in the temperature of the shells, a decrease in both components in the emissivity of the material (Planck function and absorption coefficient), respectively, a decrease in the constant component of radiation and an increase in the modulation depth of the radiation.

The results of numerous computational experiments allow us to make certain conclusions about the degree of dependence of the peak radiation power in given regions of the spectrum and the depth of radiation modulation on a set of determining factors.

A significant increase in the peak radiation power is achieved with an increase in the diameter of the discharge gap while maintaining the remaining parameters (geometrical, electrical, and physical). Thus, an increase in the diameter from 7 to $11 \mathrm{~mm}$ increases the peak radiation power by $20-25 \%$, and the constant component of the radiation of the shells decreases by almost 
V.M. Gradov, S.V. Gavrish, I.V. Rudakov

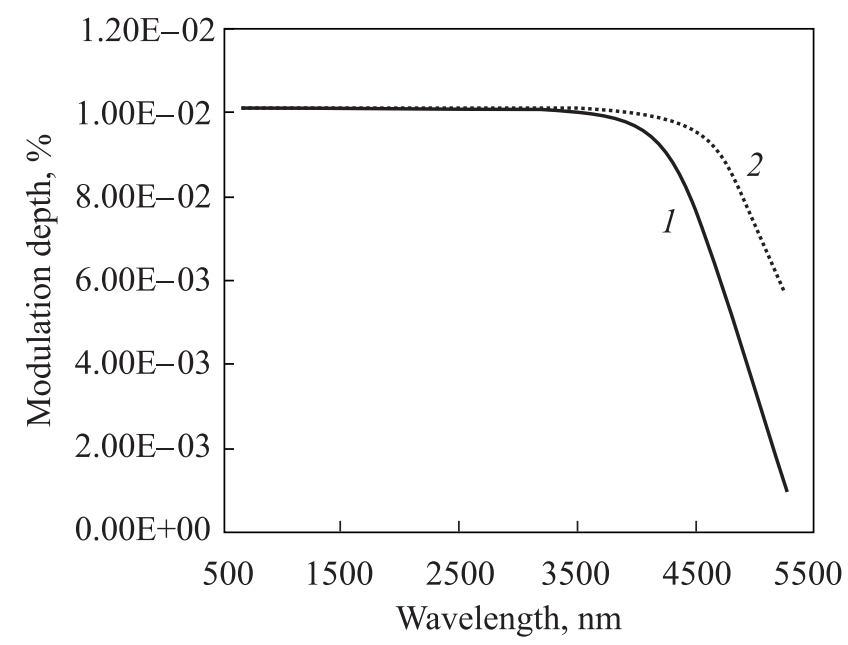

Fig. 7. The radiation modulation depth depending on the wavelength;

average electrical power $P_{s}=365 \mathrm{~W} / \mathrm{cm}$ : curve 1 is $\alpha=0.001 \mathrm{~W} /\left(\mathrm{cm}^{2} \cdot \mathrm{K}\right)$; curve 2 is $\alpha=0.01 \mathrm{~W} /\left(\mathrm{cm}^{2} \cdot \mathrm{K}\right)$

1.5 times. The temperature mode of the shells becomes more moderate and it is possible to increase by almost $40 \%$ the power invested in the lamp, with a corresponding increase in the power of the useful signal. A further increase in the diameter of the discharge tube retains a tendency for a certain increase in peak radiation power, which suggests the creation of IR emitters of new geometries with a developed outer surface such as a cavity lamp.

Replacing the buffer gas (xenon with krypton) at initial pressures that differ within 30-40 \% does not give effect and even leads to a decrease in peak radiation power.

The change in the duty arc current affects the resistance of the plasma column and the process of establishing the repetitive pulse mode, and in each case it is necessary to optimize the discharge circuit and the filling composition. Certain reserves of increasing the peak radiation power are in the correct choice of the current pulse shape, for which, in terms of energy, a quick increase at the end of the pulse is preferable. At high frequencies (the order of kilohertz) of pulse repetition, the front and rear edges of adjacent pulses overlap, as a result of which a kind of new constant component of radiation appears and the depth of radiation modulation decreases. Reducing the duration of the glow at the trailing edge of the pulse can be achieved by reducing the pressure of mercury and the buffer gas. For example, reducing the pressure of xenon by 2 times reduces the afterglow by more than 1.5 times.

The most radical way to increase the peak radiation power is to switch to new fillings (electronegative gases such as chlorine, bromine, and alkaline 
earth metals, for example, barium). Retains its relevance and the use of active filtering of radiation (using interference coatings).

The constant component of radiation is formed by the radiation of the shells, and at high frequencies also by the overlapping of the radiation pulses. Several ways to reduce the constant component of radiation due to heated shells are worthy of attention.

The geometrical dimensions of the shells (diameters, thickness of glasses, gaps between the shells), spectral optical properties of the material of the shells, composition and intensity of thermal loads on the wall, cooling conditions, gas properties in the gap between the shells have a certain effect on the constant component of radiation.

The relatively weak effect on the constant component of the radiation has the shell thickness, the size of the gaps between the shells, the diameters, and the composition of the heat transfer gas in the gap. Optimization by these parameters can provide an effect up to 10-18 \%. The cooling parameters have a strong effect on the constant component of radiation. Changing the heat transfer coefficient by 2 times changes the constant component of radiation by almost 30-50 \% (depending on the spectrum interval). The intensity of cooling can be increased by increasing the flow rates of the cooler and reducing the cross section of its flow, the transition from the longitudinal to the transverse and on the structure with a single shell. But in the latter case, a very high stability of the cooling path is required. For all the listed points, the cumulative effect may be as high as tens of percent.

It is clear that large reserves of reducing the constant component of radiation are contained in such a characteristic of the shell material as the absorption coefficient. Here, both the coefficient values in the transparency region and the long-wavelength boundary of the transmission region and the degree of surface blackness are important. We can formulate the requirements for the material, which provide a noticeable decrease in the constant component of radiation (by tens of percent). We also point out the moderate influence of the ambient temperature on the basic characteristics of the IR emitter.

The given data satisfactorily describe the extensive experimental material available to the authors.

Conclusion. The factors that determine such important performance characteristics of high-power infrared radiation sources (1.8-4.2 and 3-5 $\mu \mathrm{m}$ ) with sapphire shells, such as the depth of radiation modulation and peak radiation power, are considered. It is shown that in the steady-state operating mode, the temperature field in the shells is almost stationary and generates a constant component of radiation, increasing with increasing electrical power 
V.M. Gradov, S.V. Gavrish, I.V. Rudakov

and negatively affecting the depth of radiation modulation. It was found that, by varying the composition of the filling, it is possible to achieve an increase of 25-30\% in the constant component of the radiation with a corresponding increase in the modulation depth of the radiation. Increasing the burner diameter does not give a noticeable effect. The contribution of various mechanisms to the total energy losses on the shell has been identified. Depending on a number of defining parameters, an analysis was made of the temperature state of heated shells, the radiation of which may exceed discharge radiation in spectral regions, where the factor of the high absorption coefficient of leucosapphire is added to the factor of the corresponding position of the maximum of the Planck distribution function determined by the shell temperature. The spectral dependence of the modulation depth of the radiation at different heat-transfer coefficients is identified, it is shown that there is a long-wavelength limit beyond which the modulation depth of the radiation is zero. Ways to improve the performance of lamps are shown. The results obtained allow us to correctly interpret the experimental data and reasonably develop projects of new devices.

Translated by V. Shumaev

\section{REFERENCES}

[1] Zubov A. Aircraft protection system from MANTA man-portable air defense systems. Zarubezhnoe voennoe obozrenie, 2012, no. 1, pp. 63-67 (in Russ.).

[2] El'tsin S.N., Zhukov A.P., Kashin V.M., et al. Otsenka effektivnosti perenosnykh zenitnykh raketnykh kompleksov [Efficiency assessment of man-portable air defense systems]. St. Petersburg, Balt. GTU Publ., 2007.

[3] Shcherbinin R. Homing heads of advanced foreign guided missiles and air bombs. Zarubezhnoe voennoe obozrenie, 2009, no. 4, pp. 64-68 (in Russ.).

[4] Shcherbinin R. Aircraft self-defense system from man-portable air defense systems. Zarubezhnoe voennoe obozrenie, 2005, no. 12, pp. 37-42 (in Russ.).

[5] Ol'gin S. Problems of optoelectronic countermeasures. Zarubezhnoe voennoe obozrenie, 2002, no. 9, pp. 35-41 (in Russ.).

[6] Gavrish S.V., Gradov V.M., Terent'yev Yu.I. Construction and working features of lams with sapphire shells. Svetotekhnika, 2008, no. 2, pp. 12-18 (in Russ.).

[7] Gradov V.M., Gavrish S.V., Rudakov I.V. Simulation of electrophysical processes in pulse-periodic tubular sources of powerful infrared radiation with sapphire shells. Vestn. Mosk. Gos. Tekh. Univ. im. N.E. Baumana, Priborostr. [Herald of the Bauman Moscow State Tech. Univ., Instrum. Eng.], 2017, no. 6, pp. 130-145 (in Russ.).

DOI: 10.18698/0236-3933-2017-6-130-145

[8] Zel'dovich Ya.B., Rayzer Yu.P. Fizika udarnykh voln i vysokotemperaturnykh gidrodinamicheskikh yavleniy [Physics of shock waves and high-temperature hydrodynamic phenomena]. Moscow, Fizmatlit Publ., 2008.

14 ISSN 0236-3941. Вестник МГТУ им. Н.Э. Баумана. Сер. Машиностроение. 2019. № 1 
Thermal Mode of Sapphire Shells and Depth of Modulation of Radiation...

[9] Mitchner M., Kruger Ch.H. Partially ionized gases. Wiley, 1973.

[10] Zhdanov V.M. Protsessy perenosa v mnogokomponentnoy plazme [Transfer processes in multi-component plasma]. Moscow, Fizmatlit Publ., 2009.

[11] Gradov V.M., Terent'yev Yu.I., Shcherbakov A.A. Calculation of thermophysical properties of $\mathrm{SiO}_{2}$-based multicomponent plasma. Izvestiya SO AN SSSR. Seriya tekhnicheskikh nauk, 1982, vol. 3, no. 1, pp. 86-95 (in Russ.).

[12] Atomic spectra database. NIST: website.

Available at: https://www.nist.gov/pml/atomic-spectra-database (accessed: 21.10.18).

[13] Saloman E.B. Energy levels and observed spectral lines of xenon, Xe I through Xe LIV. J. Phys. Chem. Ref. Data, 2004, vol. 33, no. 3, pp. 765-921. DOI: 10.1063/1.1649348

[14] Sansonetti J.E. Wavelength, transition probabilities and energy levels for the spectra of cesium (Cs I-Cs LV). J. Phys. Chem. Ref. Data, 2009, vol. 38, no. 4, pp. 761-923. DOI: $10.1063 / 1.3132702$

[15] Saloman E.B. Wavelength, energy levels classifications and energy levels for the spectrum of neutral mercury. J. Phys. Chem. Ref. Data, 2006, vol. 35, no. 4, pp. 15191548. DOI: $10.1063 / 1.2204960$

[16] Kalitkin N.N. Chislennye metody [Numerical methods]. St. Petersburg, BKhV-Peterburg Publ., 2010.

[17] Samarskiy A.A., Vabishchevich P.N. Chislennye metody resheniya zadach konvektsii-diffuzii [Numerical methods for solving convection-diffusion problems]. Moscow, Librokom Publ., 2015.

[18] Eliseev V.N., Tovstonog V.A., Borovkova T.V., et al. Thermostability of casings of gasdischarge tubular water-cooled radiation sources in nonstationary state. Vestn. Mosk. Gos. Tekh. Univ. im. N.E. Baumana, Mashinostr. [Herald of the Bauman Moscow State Tech. Univ., Mechan. Eng.], 2016, no. 2, pp. 45-59 (in Russ.).

DOI: $10.18698 / 0236-3941-2016-2-45-59$

Gradov V.M. - Dr. Sc. (Eng.), Professor, Department of Computer Software and Information Technology, Bauman Moscow State Technical University (2-ya Baumanskaya ul. 5, str. 1, Moscow, 105005 Russian Federation).

Gavrish S.V. - Cand. Sc. (Eng.), Head of Research and Production Complex of Special Radiation Sources, JSC Special Design Bureau ZENIT (Panfilovskiy prospekt 10, Zelenograd, Moscow, 124489 Russian Federation).

Rudakov I.V. - Cand. Sc. (Eng.), Head of Department of Computer Software and Information Technology, Bauman Moscow State Technical University (2-ya Baumanskaya ul. 5, str. 1, Moscow, 105005 Russian Federation).

\section{Please cite this article as:}

Gradov V.M., Gavrish S.V., Rudakov I.V. Thermal Mode of Sapphire Shells and Depth of Modulation of Radiation of Pulsed-Periodic Sources of Infrared Radiation. Herald of the Bauman Moscow State Technical University, Series Mechanical Engineering, 2019, no. 1, pp. 4-15. DOI: 10.18698/0236-3941-2019-1-4-15 